\title{
Gender and social mobility modify the effect of birth weight on total and central obesity
}

\author{
Juliana Rombaldi Bernardi, ${ }^{1}{ }^{*}$, Marcelo Zubaran Goldani ${ }^{2}$, Tanara Vogel Pinheiro², Luciano Santos Pinto Guimarães ${ }^{3}$, \\ Heloisa Bettiol ${ }^{4}$, Antônio Augusto Moura da Silva ${ }^{5}$ and Marco Antônio Barbieri ${ }^{4}$
}

\begin{abstract}
Background: Little is known about the interaction between gender and low birth weight (LBW) and lifelong social mobility as an explanation of the etiology of obesity. The aim of the present study was to evaluate total and central obesity according to gender, LBW and social mobility, within the context of the epidemiological transition in middleincome countries. We hypothesize that there are more pronounced metabolic consequences of social mobility for women born with LBW.

Methods: We used data from a birth cohort study conducted in Ribeirão Preto, São Paulo, Brazil. Data regarding anthropometric measurements, schooling and smoking status were collected at 23-25 years of age. Social mobility was determined based on maternal and adult offspring schooling and categorized as Low-Low, Low-High and High-High. Analysis of covariance was performed to assess the association between social mobility and body mass index (BMI) or waist circumference (WC) in adulthood, stratified by LBW and gender.

Results: Data on 6827 singleton pregnancies were collected at birth in 1978/79 and a sample was followed up in 2002/04. A total of 2063 subjects were included in the study. Mean age was $23.9 \pm 0.7$ years, $51.8 \%(n=1068)$ were female and the LBW was $6.2 \%(n=128)$. There was a triple interaction between social mobility, LBW and gender. Among women born without LBW, BMI and WC were higher in the Low-Low group compared to High-High schooling group. Among LBW women, BMI and WC were higher in the Low-Low group compared to the Low-High group.

Conclusions: Women born with LBW belonging to the low schooling group in early adulthood had high BMI and WC, compared to the Low-High social mobility group.
\end{abstract}

Keywords: Early life programming, Birth weight, Social transition, Body mass index, Waist circumference

\section{Background}

A number of hypothetical models have been proposed over the last fifty years in order to explain the changes in the pattern of health and disease [1-4]. There are models proposing a perspective of epidemiological transition based on the presence of early life stress and environmental adequacy during the life course, which could

\footnotetext{
* Correspondence: juliana.bernardi@yahoo.com.br

'Departamento de Nutrição, Universidade Federal do Rio Grande do Sul, Av. Jerônimo de Ornelas, 721 - Santana, 90040-341 Porto Alegre, Rio Grande do Sul, Brazil

${ }^{2}$ Departamento de Medicina, Programa de Pós-Graduação em Saúde da Criança e do Adolescente, Universidade Federal do Rio Grande do Sul, Rua Ramiro Barcelos, 2400, Santana, 90035-003 Porto Alegre, Rio Grande do Sul, Brazil Full list of author information is available at the end of the article
}

influence metabolic patterns in adulthood [3, 5-8]. In addition, there are evidences that the maternal capital hypothesis, a phenotypic change dampened by maternal buffering, was mainly raised to address associations between social and health inequality [9-11]. From an evolutionary perspective, a recent study found that individuals whose mothers were young, who belonged to an ethnic minority, and who breastfed for a short period of time were more likely to be obese in adulthood, after controlling for factors present in infancy, adolescence, and adulthood [10].

Previous studies have shown that social improvement has a positive immediate influence on metabolic markers of vulnerable social groups after adjustment for potential 
confounders and that this influence is different for men and women [12-14]. Heraclides and Brunner, using retrospective data from a cross-sectional study of 4598 participants, observed that social mobility and social accumulation (social advantage or disadvantage) were associated with the development of overweight and obesity in adulthood, with stronger effects among women [15]. Also, a study published by our research group, in Brazil found that increase income in early adulthood was associated with a significant reduction in body mass index (BMI), waist circumference (WC) and waist-to-hip ratio only in females [16], supporting the evidence that upward social mobility may have different implications according to gender.

Brazil, like other middle-income countries, has been involved in an process of social and demographic transition with reduction of infant mortality, increase in life expectancy and improvements in social standards [17]. On the other hand, the country still has high rates of low birth weight (LBW) in infants when compared to developed countries $[18,19]$. There are evidences that an individual's birth weight, considered a strong proxy when controlling for confounders, can be a correlate of a harsh environment or vulnerable condition with respect to adult health status [20,21]. Thus, researchers have been investigating the relationship between infant birth weight and social family determinants during childhood [22-24]. On this scenario, studies of early life stress, as indexed by LBW, followed by social mobility, could provide insights about changes in health and disease patterns, especially regarding the etiology of obesity $[25,26]$.

The objective of the present study was to evaluate the influence of social mobility during the life course on BMI and WC of individuals who experienced the epidemiological transition in Brazil (1978/1979 and 2002/2004) stratified by gender and birth weight.

\section{Methods}

\section{Sample and participants}

We analyzed prospective data from the Ribeirão Preto Cohort Study, collected in 1978/1979 and 2002/2004. Ribeirão Preto is a city of over half-a-million inhabitants in the urbanized South East of Brazil (São Paulo). The first phase of the study lasted from June, 1978 to May, 1979. A total of 9067 newborn babies were included ( $98 \%$ of all live births in the city over that period). Subjects who were not from Ribeirão Preto or did not reside in the city at the time of delivery $(n=2094)$ were excluded, with the final sample consisting of 6973 liveborns (6827 singletons and 146 twin pairs). The second phase of cohort follow up started in $1994(n=2846)$ and the third phase started in 1996/97 $(n=2048)$.

The fourth cohort follow-up was started in 2002/2004, when the individuals were 23-25 years old. From the original cohort, of 6827 singletons, 343 had died and 819 could not be located during follow-up; thus, 5665 individuals living in the same geo-economic area were contacted, corresponding to $30 \%$ of the calculated sample size of the eligible population. Updated addresses were retrieved from a number of databases including the Unified Health System (SUS) electronic database, lists of users of private health plans, school charts, and military recruitment charts. Losses to follow-up $(n=705)$ occurred because of refusal to participate, imprisonment or failure to attend an interview. These losses were replaced using the same sampling frame, resulting in 2063 young adults $(n=995$ males and $n=1068$ females). The protocol methodology and sample characteristics have been published elsewhere $[27,28]$.

\section{Outcomes}

Anthropometric outcomes: trained staff measured weight and height, with the person barefoot and wearing light clothing. BMI was calculated by dividing weight (in kilograms, $\mathrm{kg}$ ) by squared height (in squared meters, $\mathrm{m}^{2}$ ) [29]. Height at adult age was measured to the nearest centimeter using a wood and Formica stadiometer resistant to deformation. Weight was measured with a Filizola ${ }^{\circ}$ scale (São Paulo, SP, Brazil) with 100 g graduations and with $140 \mathrm{~kg}$ capacity. WC was measured as the smallest circumference (in centimeters, $\mathrm{cm}$ ) between the ribs and the iliac crest, while the participant was standing with the abdomen relaxed, at the end of a normal expiration.

\section{Covariates}

Child's birth weight: was measured with appropriate devices donated by the research team to all hospitals. The babies were naked and were weighed on weekly calibrated scales with $10 \mathrm{~g}$ precision and classified as low birth weight $(<2500 \mathrm{~g})$ or not low birth weight $(\geq 2500 \mathrm{~g})$.

Social mobility: calculated by the authors using maternal schooling (in years) and adult offspring schooling (in years) at the time of the interview, was classified as low (schooling between 0-8 years) or high (schooling $\geq$ 9 years). Maternal schooling at birth was used as a proxy of offspring socioeconomic status (SES) during childhood. Maternal schooling was chosen due to its significance in the contemporary socioeconomic context, with current association with material and nonmaterial goods, such as access to information and behavior in the presence of health challenges, and social status [30].

The four possible classifications of social mobility were: Stable Low-Low (Low-Low group), Ascending Low-High (Low-High group), Descending High-Low (High-Low group) and Stable High-High (High-High group). The High-Low (High-Low group) category was excluded from analysis because there were only 13 individuals. 


\section{Confounders}

The model was adjusted for smoking during pregnancy (smoker and nonsmoker, determined during a postpartum interview) and gestational age (in weeks) because the variables were associated with birth weight.

\section{Statistical analysis}

Categorical variables were expressed as absolute $(n)$ and relative (\%) frequencies. Continuous variables were expressed as mean, standard deviation (SD) and 95\% confidence intervals (CI). The Chi-square test was performed to analyze categorical variables and analysis of variance (three way-ANOVA) to compare continuous variables, followed by the Bonferroni post hoc test, when indicated.

We examined the metabolic outcomes (BMI and WC) according to birth weight (LBW and no LBW), social mobility (Low-Low group, High-Low group and HighHigh group) and gender (female and male) calculating population averages and testing for a trend. Analysis of covariance (ANCOVA), followed by the Bonferroni post hoc test, when indicated, was performed by adding the factors sequentially.

Data were analyzed using the Statistical Package for the Social Sciences ${ }^{\bullet}$ (SPSS) version 18.0 software (SPSS Inc., Chicago, IL, USA). The levels of significance were set at $P<0.05$ in all analyses.

\section{Ethical aspects}

This cohort study was approved by the Research Ethics Committee of Hospital das Clinicas de Ribeirão Preto, Faculdade de Medicina de Ribeirão Preto, Universidade de São Paulo (protocol HCRP n. 7606/99), Brazil.

All subjects gave written informed consent to participate in the cohort study.

\section{Results}

A total of 2063 subjects were included in the study and sample size varied for each variable. The mean $( \pm \mathrm{SD})$ age of the young adults was $23.9 \pm 0.7$ years and $51.8 \%$ $(n=1068)$ were female. The LBW rate was $6.2 \%(n=128)$ and $27.0 \%(n=546)$ of mothers and $84.5 \%(n=1743)$ of the adult offspring had high schooling ( $\geq 9$ years).

The maternal and adulthood variables are shown in Table 1. LBW was significantly more common among low education mothers ( $P=0.007$; values: $83.9 \%$ vs. $72.3 \%)$ and among mothers who smoked any time during pregnancy ( $P<0.001$; values: $44.8 \%$ vs. $24.1 \%$ ) when compared to non LBW. As expected, there was an association between birth weight $<2500 \mathrm{~g}$ and lower gestational age $(P$ $<0.001$; values: $34.1 \%$ vs. $5.7 \%$ ). Individuals born with LBW had significantly less education $(P<0.001$; values: $27.3 \%$ vs. $14.7 \%$ ) when compared to non LBW. No other statistically significantly differences were found $(P>0.05)$.
Table 1 Maternal and adulthood characteristics according to birth weight, 1978/79 Ribeirão Preto Birth Cohort

\begin{tabular}{|c|c|c|c|c|c|}
\hline \multirow[t]{2}{*}{ Variables } & \multicolumn{2}{|c|}{$\begin{array}{l}\text { Birth weight } \\
\geq 2500 \mathrm{~g} \\
(n=1935)\end{array}$} & \multicolumn{2}{|c|}{$\begin{array}{l}\text { Birth weight } \\
<2500 \mathrm{~g} \\
(n=128) \\
\end{array}$} & \multirow[t]{2}{*}{$p^{*}$} \\
\hline & $N$ & $\%$ & $n$ & $\%$ & \\
\hline \multicolumn{6}{|l|}{ Maternal } \\
\hline \multicolumn{6}{|c|}{ Schooling (years) ${ }^{a}$} \\
\hline High & 526 & 27.7 & 20 & 16.1 & 0.007 \\
\hline Low & 1373 & 72.3 & 104 & 83.9 & \\
\hline \multicolumn{6}{|l|}{ Age (years) ${ }^{a}$} \\
\hline$<19$ & 140 & 7.3 & 13 & 10.2 & 0.429 \\
\hline $19-34$ & 1622 & 84.3 & 105 & 82.7 & \\
\hline$\geq 35$ & 162 & 8.4 & 9 & 7.1 & \\
\hline \multicolumn{6}{|c|}{ Smoking during pregnancy ${ }^{a}$} \\
\hline Nonsmoker & 1441 & 75.9 & 69 & 55.2 & $<0.001$ \\
\hline Smoker & 457 & 24.1 & 56 & 44.8 & \\
\hline \multicolumn{6}{|l|}{ Type of delivery } \\
\hline Vaginal & 1314 & 67.9 & 88 & 68.7 & 0.920 \\
\hline Caesarean & 621 & 32.1 & 40 & 31.3 & \\
\hline \multicolumn{6}{|c|}{ Gestational age (weeks) a } \\
\hline$\geq 37$ & 1460 & 94.3 & 58 & 65.9 & \\
\hline$<37$ & 88 & 5.7 & 30 & 34.1 & $<0.001$ \\
\hline \multicolumn{6}{|l|}{ Adulthood } \\
\hline \multicolumn{6}{|c|}{ Schooling (years) } \\
\hline High & 1650 & 85.3 & 93 & 72.7 & $<0.001$ \\
\hline Low & 285 & 14.7 & 35 & 27.3 & \\
\hline \multicolumn{6}{|l|}{ Gender } \\
\hline Male & 942 & 48.7 & 53 & 41.4 & 0.133 \\
\hline Female & 993 & 51.3 & 75 & 58.6 & \\
\hline \multicolumn{6}{|l|}{ Smoking status } \\
\hline Nonsmoker & 1607 & 83.0 & 102 & 79.7 & 0.392 \\
\hline Smoker & 328 & 17.0 & 26 & 20.3 & \\
\hline
\end{tabular}

${ }^{a}$ Totals may not add up to $n=2063$ because of missing values

${ }^{*} P$ refers to the chi-squared test

Bold text: Significant differences between groups $(P<0.05)$

The distribution of BMI and WC according to birth weight, social mobility and gender is shown in Table 2 (univariate analyses) and in Table 3 (multivariate analyses). Figures 1 (BMI) and 2 (WC) show the trajectory of BMI and WC by gender, social mobility and birth weight.

There were no statistically significant interactions between the outcomes, social mobility and birth weight $(P>0.05)$ or between gender and birth weight $(P>0.05)$. However, in the crude and adjusted model, there was a statistically significant interaction between social mobility and gender $(P<0.05)$ and a triple interaction between social mobility, birth weight and gender $(P<0.05)$. 
Table 2 Univariate analysis between BMI and WC according to birth weight and social mobility, 1978/79 Ribeirão Preto Birth Cohort

\begin{tabular}{|c|c|c|c|c|c|c|c|}
\hline Social Mobility & Gender & Birth weight & & $P^{*}$ & $P^{* *}$ & $P^{* * *}$ & $P^{* * * *}$ \\
\hline \multirow[t]{2}{*}{$\mathrm{BMI}\left(\mathrm{kg} / \mathrm{m}^{2}\right)$} & & Mean (IC 95\%)† & & & & & \\
\hline & & $\geq 2500 \mathrm{~g}(n=1880)$ & $<2500 \mathrm{~g}(n=123)$ & & & & \\
\hline High-High $(n=533)$ & $\begin{array}{l}\text { Males } \\
\text { Females }\end{array}$ & $\begin{array}{l}25.1[24.6-25.7]^{\mathrm{A}} \\
22.3[21.8-22.9]^{\mathrm{a}, \mathrm{B}}\end{array}$ & $\begin{array}{l}25.2[21.7-28.7] \\
24.6[21.9-27.2]^{\mathrm{ab}}\end{array}$ & 0.074 & 0.190 & 0.022 & 0.030 \\
\hline Low-High $(n=1170)$ & $\begin{array}{l}\text { Males } \\
\text { Females }\end{array}$ & $\begin{array}{l}24.8[24.4-25.2]^{\mathrm{A}} \\
23.9[23.5-24.3]^{\mathrm{b}, \mathrm{B}, \mathrm{a}}\end{array}$ & $\begin{array}{l}24.7[22.9-26.5]^{\mathrm{A}} \\
22.1[20.7-23.5]^{\mathrm{a}, \mathrm{B}, \gamma}\end{array}$ & & & & \\
\hline Low-Low $(n=300)$ & $\begin{array}{l}\text { Males } \\
\text { Females }\end{array}$ & $\begin{array}{l}25.4[24.6-26.2] \\
24.7[23.9-25.5]^{\mathrm{b}, a}\end{array}$ & $\begin{array}{l}24.7[22.5-27.0] \\
27.6[25.4-29.9]^{b, \gamma}\end{array}$ & & & & \\
\hline \multirow[t]{2}{*}{ WC (cm) } & & Mean (IC 95\%)† & & & & & \\
\hline & & $\geq 2500 \mathrm{~g}(n=1885)$ & $<2500 \mathrm{~g}(n=123)$ & & & & \\
\hline High-High $(n=533)$ & $\begin{array}{l}\text { Males } \\
\text { Females }\end{array}$ & $\begin{array}{l}88.1[86.7-89.5]^{\mathrm{A}} \\
73.8[72.3-75.2]^{\mathrm{a}, \mathrm{B}}\end{array}$ & $\begin{array}{l}86.6[78.1-95.2] \\
77.8[71.2-84.3]^{\mathrm{ab}}\end{array}$ & 0.100 & 0.082 & 0.007 & 0.017 \\
\hline Low-High $(n=1172)$ & $\begin{array}{l}\text { Males } \\
\text { Females }\end{array}$ & $\begin{array}{l}87.2[86.2-88.2]^{\mathrm{A}} \\
77.4[76.5-78.4]^{\mathrm{b}, \mathrm{B}, \mathrm{a}}\end{array}$ & $\begin{array}{l}86.2[81.8-90.5]^{\mathrm{A}} \\
73.1[69.6-76.6]^{\mathrm{a}, \mathrm{B}, \mathrm{V}}\end{array}$ & & & & \\
\hline Low-Low $(n=303)$ & $\begin{array}{l}\text { Males } \\
\text { Females }\end{array}$ & $\begin{array}{l}88.8[86.8-90.7]^{\mathrm{A}} \\
79.6[77.6-81.5]^{\mathrm{b}, \mathrm{B}, \mathrm{a}}\end{array}$ & $\begin{array}{l}85.7[80.2-91.2] \\
87.5[82.0-93.0]^{b, y}\end{array}$ & & & & \\
\hline
\end{tabular}

$P$ refers to three-way ANOVA (Bonferroni post hoc pairwise comparison)

†Value expressed as mean and $95 \%$ confidence interval

Different small letters denote statistically significant differences according to gender and birth weight and by social mobility $(P<0.05)$

Different capital letters denote statistically significant differences according to social mobility and birth weight and by gender $(P<0.05)$

Different Greek letters denote statistically significant differences according to social mobility and gender and by birth weight $(P<0.05)$

*P: outcomes vs. interaction between social mobility and birth weight

**P: outcomes vs. interaction between gender and birth weight

***P: outcomes vs. interaction between social mobility and gender

****P: outcomes vs. interaction between social mobility, birth weight and gender

$B M I$ body mass index, WC waist circumference

Bold text: Significant differences between groups $(P<0.05)$

The biological values of males were significantly higher than those of females, specifically regarding BMI, as follows: High-High group with no LBW (values: $22.3 \mathrm{~kg} / \mathrm{m}^{2} v s .25 .1 \mathrm{~kg} / \mathrm{m}^{2}$ ), Low-High group with no LBW (values: $23.9 \mathrm{~kg} / \mathrm{m}^{2} v s .24 .8 \mathrm{~kg} / \mathrm{m}^{2}$ ) and Low-High group with LBW (values: $22.1 \mathrm{~kg} / \mathrm{m}^{2} v s .24 .7 \mathrm{~kg} / \mathrm{m}^{2}$ ). The same statistical differences were maintained in adjusted analyses. Also about WC, the male values were significantly higher than the female values, as follows: High-High group with no LBW (values: $88.1 \mathrm{~cm} v s$. $73.8 \mathrm{~cm}$ ), Low-High group with no LBW (values: $87.2 \mathrm{~cm}$ $v s .77 .4 \mathrm{~cm})$, Low-Low group with no LBW $(88.8 \mathrm{~cm} v$. $79.6 \mathrm{~cm}$ ) and Low-High group with LBW (values: $86.2 \mathrm{~cm}$ vs. $73.1 \mathrm{~cm}$ ). The same statistical differences were maintained in adjusted analyses and the values of WC in High-High group with LBW (values: $89.6 \mathrm{~cm}$ vs. $76.8 \mathrm{~cm}$ ) were higher in males than females. Gender differences are indicated by capital letters in Tables 2 and 3 .

Regarding differences in social mobility, crude analysis showed that among females born without LBW, BMI and WC were statistical higher in the Low-Low group (values: $24.7 \mathrm{~kg} / \mathrm{m}^{2}$ and $79.6 \mathrm{~cm}$ ) compared to the HighHigh group (values: $22.3 \mathrm{~kg} / \mathrm{m}^{2}$ and $73.8 \mathrm{~cm}$ ). Among LBW women, BMI and WC were significantly higher in the Low-Low group (values: $27.6 \mathrm{~kg} / \mathrm{m}^{2}$ and $87.5 \mathrm{~cm}$ ) compared to the Low-High group (values: $22.1 \mathrm{~kg} /$ $\mathrm{m}^{2}$ and $73.1 \mathrm{~cm}$ ). The same statistical differences were maintained in adjusted analyses. No statistically significant differences were found for males $(P>0.05)$. The differences in social mobility are indicated by small letters in Tables 2 and 3.

Regarding the differences in birth weight (no LBW $v s$. LBW), only among females, BMI and WC of the LowHigh group were higher in non LBW (values: $23.9 \mathrm{~kg} / \mathrm{m}^{2}$ and $77.4 \mathrm{~cm}$ ) than LBW (values: $22.1 \mathrm{~kg} / \mathrm{m}^{2}$ and $73.1 \mathrm{~cm}$ ) subjects. However, BMI and WC of the Low-Low group were higher in LBW (values: $27.6 \mathrm{~kg} / \mathrm{m}^{2}$ and $87.5 \mathrm{~cm}$ ) when compared to non LBW (values: $24.7 \mathrm{~kg} / \mathrm{m}^{2}$ and $79.6 \mathrm{~cm})$ subjects. The significant difference of the Low-High group was maintained in adjusted analyses. The differences in birth weight are indicated by Greek letters in Tables 2 and 3.

\section{Discussion}

The present results show that the metabolic consequences of social mobility are especially pronounced among adult women. There was a triple interaction between social mobility, birth weight and gender. Among LBW women, BMI and WC were significantly higher for those who did not present social mobility and who stayed in the low schooling group from birth to early adulthood. Conversely, LBW women under social mobility showed the lowest BMI and WC, changing prognoses with a rapid response to the social and possible environmental changes. Moreover, the 
Table 3 Adjusted analysis between BMI and WC according to birth weight and social mobility, 1978/79 Ribeirão Preto Birth Cohort

\begin{tabular}{|c|c|c|c|c|c|c|c|}
\hline Social Mobility & Gender & Birth weight & & $P^{*}$ & $p^{* *}$ & $p^{* * *}$ & $P^{* * * *}$ \\
\hline \multirow[t]{2}{*}{$\overline{B M I}\left(\mathrm{~kg} / \mathrm{m}^{2}\right)$} & & Mean (IC 95\%)† & & & & & \\
\hline & & $\geq 2500 \mathrm{~g}(n=1532)$ & $<2500 \mathrm{~g}(n=86)$ & & & & \\
\hline High-High $(n=471)$ & $\begin{array}{l}\text { Males } \\
\text { Females }\end{array}$ & $\begin{array}{l}25.4[24.8-26.0]^{\mathrm{A}} \\
22.5[21.9-23.1]^{\mathrm{a}, \mathrm{B}}\end{array}$ & $\begin{array}{l}26.1[22.4-29.8] \\
24.3[21.4-27.1]^{\mathrm{ab}}\end{array}$ & 0.125 & 0.277 & 0.017 & 0.044 \\
\hline Low-High $(n=931)$ & $\begin{array}{l}\text { Males } \\
\text { Females }\end{array}$ & $\begin{array}{l}25.1[24.7-25.6]^{\mathrm{A}} \\
23.9[23.5-24.4]^{\mathrm{b}, \mathrm{B}, \mathrm{a}}\end{array}$ & $\begin{array}{l}24.6[22.2-27.0]^{\mathrm{A}} \\
21.6[20.0-23.2]^{\mathrm{a}, \mathrm{B}, \mathrm{y}}\end{array}$ & & & & \\
\hline Low-Low $(n=216)$ & $\begin{array}{l}\text { Males } \\
\text { Females }\end{array}$ & $\begin{array}{l}26.1[25.2-27.0] \\
25.1[24.1-26.0]^{b}\end{array}$ & $\begin{array}{l}24.1[21.7-26.5] \\
27.5[24.8-30.2]^{b}\end{array}$ & & & & \\
\hline \multirow[t]{2}{*}{ WC (cm) } & & Mean (IC 95\%)† & & & & & \\
\hline & & $\geq 2500 \mathrm{~g}(n=1536)$ & $<2500 \mathrm{~g}(n=86)$ & & & & \\
\hline High-High $(n=471)$ & $\begin{array}{l}\text { Males } \\
\text { Females }\end{array}$ & $\begin{array}{l}88.4[86.8-89.9]^{\mathrm{A}} \\
74.1[72.6-75.7]^{\mathrm{a}, \mathrm{B}}\end{array}$ & $\begin{array}{l}89.6[80.4-98.7]^{\mathrm{A}} \\
76.8[69.7-83.9]^{\mathrm{b}, \mathrm{B}}\end{array}$ & 0.311 & 0.285 & 0.009 & 0.035 \\
\hline Low-High $(n=933)$ & $\begin{array}{l}\text { Males } \\
\text { Females }\end{array}$ & $\begin{array}{l}87.9[86.8-89.1]^{\mathrm{A}} \\
77.3[76.2-78.5]^{\mathrm{b}, \mathrm{B}, \mathrm{a}}\end{array}$ & $\begin{array}{l}86.9[80.9-92.9]^{\mathrm{A}} \\
72.2[68.2-76.2]^{\mathrm{a}^{\mathrm{B}, B_{Y}}}\end{array}$ & & & & \\
\hline Low-Low $(n=218)$ & $\begin{array}{l}\text { Males } \\
\text { Females }\end{array}$ & $\begin{array}{l}90.2[88.0-92.5]^{\mathrm{A}} \\
80.4[78.0-82.7]^{\mathrm{b}, \mathrm{B}}\end{array}$ & $\begin{array}{l}84.1[78.1-90.1] \\
86.0[79.2-92.7]^{\mathrm{b}}\end{array}$ & & & & \\
\hline
\end{tabular}

$P$ refers to Analysis of Covariance Models (ANCOVA) (Bonferroni post hoc pairwise comparison)

Model adjusted for: smoking during pregnancy, type of delivery, gestational age (39.3 weeks)

tValue expressed as mean and $95 \%$ confidence interval

Different small letters denote statistically significant differences according to gender and birth weight and by social mobility $(P<0.05)$

Different capital letters denote statistically significant differences according to social mobility and birth weight and by gender $(P<0.05)$

Different Greek letters denote statistically significant differences according to social mobility and gender and by birth weight $(P<0.05)$

*P: outcomes $v$ s. interaction between social mobility and birth weight

**P: outcomes vs. interaction between gender and birth weight

***P: outcomes vs. interaction between social mobility and gender

****P: outcomes vs. interaction between social mobility, birth weight and gender $B M I$ body mass index, WC waist circumference

Bold text: Significant differences between groups $(P<0.05)$

BMI and WC values of those with upward socioeconomic mobility (Low-High) were higher among women without LBW than among women with LBW. The results pointed out that the scenario characterized by social scarcity and lack of conditions can be overcome by social improvement [31].

Other longitudinal studies have assessed the relationship between SES mobility and metabolic outcomes. For

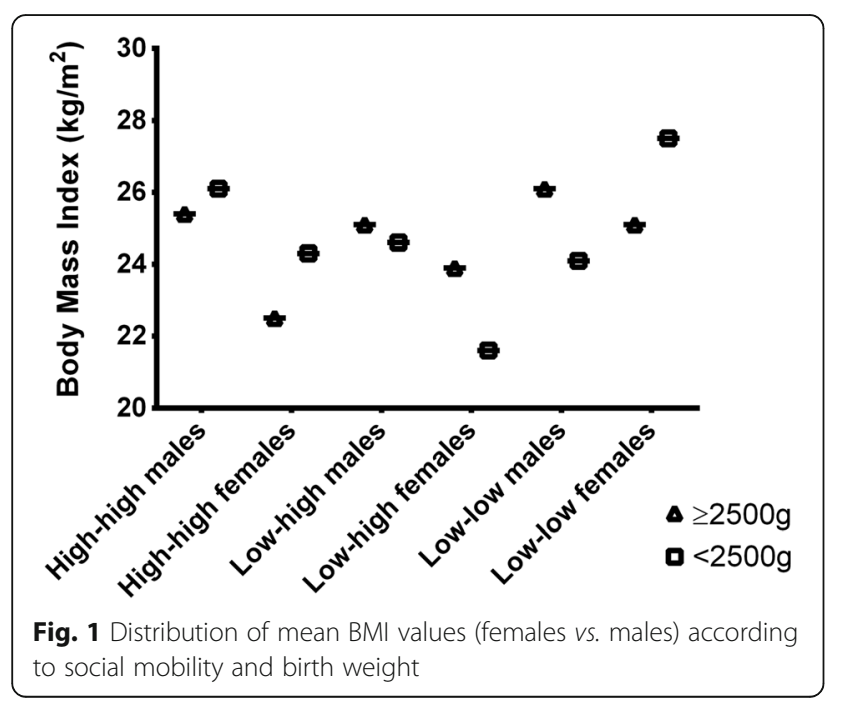

example, a study conducted in Cuiaba, Brazil, with 1716 individuals, found that the higher SES group (based on the number of home appliances, cars and paid maids, and the educational level of the head of the household and compared between pre-school and adolescence) at preschool age and among those who remained in the high SES until adolescence was positively associated with overweight between birth and adolescence [32]. In contrast, a

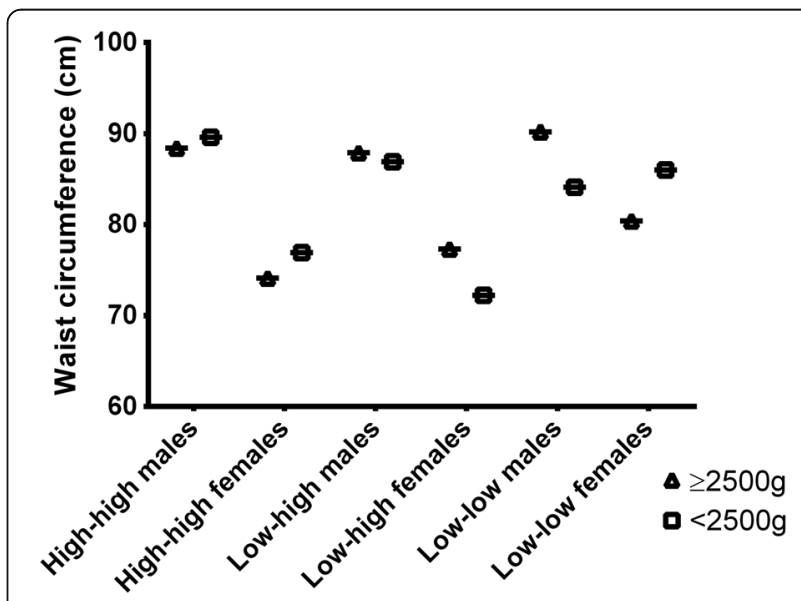

Fig. 2 Distribution of mean WC values (females vs. males) according to social mobility and birth weight 
study of United States (US) immigrants that investigated the associations between SES mobility categories (based on the educational attainment reported by individuals as adults and by their parents during adolescence) found that the upward educational mobility, compared to maintaining a low SES, was associated with a lower mean BMI [33]. Thus, these results showed a social determinant of changes in metabolic aspects and could indicate the stage of economic development of different cities. In this investigation, in contrast to the Cuiaba study and in agreement with the US study, upward social mobility protected against obesity. However, stability in the low schooling group was associated with higher BMI and WC values only among women born with LBW. However, being born in a low schooling environments and remaining with low schooling during early adult life had no effect on obesity among men or among those born LBW.

The biological explanation for the association between socioeconomic mobility and health outcomes may involve changes in stress-related processes and the cardiovascular system which is one of the most susceptible systems to stress [34]. A recent cohort study conducted in South Africa showed that an upward SES change (measured with a physical asset-based tool for the determination of household socioeconomic status) between infancy and adolescence was significantly associated with lower systolic blood pressure at the age of 18 years, compared to a persistent low SES [35].

Furthermore, we also found that higher BMI and WC values are especially pronounced among adult women born LBW (Low-Low group). However, in the Low-High group, BMI and WC values were higher in non LBW subjects compared to LBW subjects. Another populationbased cohort investigating the effect of family background and birth region on adult obesity status by gender and over the life course found that birth region and mother's education were associated with an increased obesity risk among women, but not among men [36].

In addition, the WC of the High-High group with LBW was higher among males than among females. Other studies conducted in Brazil also seem to agree about a higher risk of obesity among men who have always been in the higher socioeconomic strata, whereas the opposite has been found for women $[16,37,38]$. These findings suggest that women are experiencing the social transition (or reversal of the social gradient) much faster than men [16].

The plausible mechanisms underlying the association between an early life stress (LBW) and obesity in adulthood may involve a rapid rate of weight gain in early life or a combination of LBW and rapid postnatal catch-up growth [39]. A prospective cohort study conducted in Australia showed that rapid weight gain in the first years of life increased the risk of a higher BMI and WC in young adulthood. The authors found that the rapid growers had a significantly higher gestation period and LBW rate when compared to those who exhibited gradual or slow growth. In addition, the rate of weight gain was significantly associated with maternal education. Regarding gender differences, boys showed a higher growth rate than girls; however, when obesity status was classified by WC measurements at 21 years, more females were overweight than males [40].

Another explanation could be the long-term health implications of caesarean section (CS) delivery [41, 42] and the effect of changes in the gut microbiota [43-45]. Data from a Brazilian study obtained from SINASC (Brazilian Live Births Database) suggest a non-linear trend association. When CS rates were about 30\%, LBW rates tended to decline as CS increased. On the other hand, when the rates were higher than $30 \%$, LBW rates tended to increase with CS [18]. However, CS rates are lower in private social groups, and therefore the results do not support this hypothesis. In addition, the interaction between type of delivery and maternal BMI is also important, with maternal obesity and CS having been associated with changes in the microbiota of newborns. Unfortunately, we do not have information about maternal BMI in order to explore its impact on offspring BMI and WC. Moreover, there are many environmental determinants and psychological factors involved to the predictors of obesity which mediate the association with LBW, such as maternal cigarette smoking, maternal education and inadequate maternal nutrition [46]. Regarding gender differences in social patterning, social childhood exposure seems to influence later life outcomes, including biological programming during critical periods of growth and the early acquisition an unhealthy lifestyle [47]. Furthermore, this gender effect on outcome can be modified by birth weight.

Regarding the different metabolic outcomes between genders, a study of the same cohort in Ribeirão Preto, São Paulo, Brazil, revealed that the association between BMI at birth and adulthood BMI occurred only among women, suggesting that prevention policies should consider gender-specific strategies [48]. Moreover, in another birth cohort, the authors found differences between men and women: BMI was lower in men of low SES than in men of high SES but was higher in women of low SES than in women of high SES [49]. These different gender results may be explained by differences in in utero programming epigenetic mechanisms in addition to health and feeding behavior. In a review explaining the sexspecific adaptation of causal variables to environmental perturbations, when the sex of the embryo was taken into account. Most human studies showed sexual dimorphism in placental function and a specific sexually dimorphic response to maternal diet [50]. Using data from a township in South Africa, the authors observed that women who 
were nutritionally deprived as children are more likely to be obese as adults, whereas men who were deprived as children appear to face no greater obesity risk [51]. The contribution to obesity can be justified by the fact that women from a Brazilian birth cohort, especially those born with severe intrauterine growth restriction, measured by the birth weight ratio, preferred carbohydrates to protein in their regular diet [52].

The effects of social determinants on total and central obesity agree with theories of disease etiology involving fetal programming and their interactions according to gender and should be investigated more fully [8]. To investigate the effect of neighborhood changes on metabolic outcomes, a randomized social experiment involving a total of 4498 families showed that the prevalence of extreme obesity and diabetes decreased with the opportunity to move from a neighborhood with a high level of poverty to a less underprivileged one [31]. Complementarily, a study with the same design also found that neighborhood environments affects the well-being of low-income adult [53].

Regarding study limitation, in the cited birth cohort, no information was obtained about maternal obesity (measured by BMI or body composition). In contrast, the size of our birth cohort is relatively large and the data were collected during transition periods.

\section{Conclusions}

In summary, the present results indicate that, among females, the stable Low-Low schooling group had higher $\mathrm{BMI}$ and WC values, suggesting that the individuals maintained a low schooling level, with less access to health services, to the conditions needed to maintain a healthy lifestyle and to knowledge of issues related to disease prevention. However, being born with LBW in a "low schooling" environment and achieving high educational level (Low-High group) was associated with less detrimental metabolic features. On the other hand, not being born LBW in a "high schooling" environment, achieving a high educational level (High-High group) was associated with less detrimental metabolic features. Essentially, we found that social mobility does not affect total (BMI) and central obesity (WC) in the same direction.

\section{Abbreviations \\ ANCOVA: Analysis of covariance; ANOVA: Analysis of variance; BMI: Body mass index; CNPq: Brazilian Research Council; CS: Caesarean section; LBW: Low birth weight; SD: Standard deviation; SES: Socioeconomic status; SINASC: Brazilian Live Births Database; SPSS: Statistical Package for the Social Science; US: United States; WC: Waist circumference}

\section{Acknowledgements}

We thank the Brazilian Research Council (CNPq), the University of Sao Paulo and the Sao Paulo Research Foundation (grant number 2000/09508-7) for financial support.

\section{Funding}

This Ribeirao Preto Cohort Study was supported by Fundação de Apoio à Pesquisa do Estado de São Paulo-FAPESP, Conselho Nacional de Desenvolvimento Científico e Tecnológico and FAEPA-HCFMRP-USP, Brazil.

\section{Availability of data and materials not applicable.}

\section{Authors' contributions}

$M Z G, H B$, AAMS and MAB designed the research; $H B, A A M S$ and MAB provided essential materials (database); JRB, MZG, TVP, LSPG and AAMS analyzed the data; JRB, MZG, TVP and AAMZ wrote the manuscript; and JRB and MZG had primary responsibility for the final content. All authors read and approved the final manuscript.

\section{Competing interests}

The authors declare that they have no competing interests.

\section{Consent for publication}

the authors declare no potential competing interests.

\section{Ethics approval and consent to participate}

Research Ethics Committee of Hospital das Clinicas de Ribeirão Preto, Faculdade de Medicina de Ribeirão Preto, Universidade de São Paulo (protocol HCRP n. 7606/99), Brazil. All subjects gave written informed consent to participate in the cohort study.

\section{Publisher's Note}

Springer Nature remains neutral with regard to jurisdictional claims in published maps and institutional affiliations.

\section{Author details}

'Departamento de Nutrição, Universidade Federal do Rio Grande do Sul, Av. Jerônimo de Ornelas, 721 - Santana, 90040-341 Porto Alegre, Rio Grande do Sul, Brazil. ${ }^{2}$ Departamento de Medicina, Programa de Pós-Graduação em Saúde da Criança e do Adolescente, Universidade Federal do Rio Grande do Sul, Rua Ramiro Barcelos, 2400, Santana, 90035-003 Porto Alegre, Rio Grande do Sul, Brazil. ${ }^{3}$ Unidade de Bioestatística, Grupo de Pesquisa e Pós-graduação, Hospital de Clínicas de Porto Alegre, Rua Ramiro Barcelos, 2350, Santa Cecilia, 90035-903 Porto Alegre, Rio Grande do Sul, Brazil. ${ }^{4}$ Departamento de Puericultura e Pediatria, Faculdade de Medicina de Ribeirão Preto, Universidade de São Paulo, Av. Bandeirantes, 3900 - Monte Alegre, Ribeirão Preto, São Paulo 14049-900, Brazil. ${ }^{5}$ Departamento de Saúde Pública, Universidade Federal do Maranhão, Av. dos Portugueses, 1966 - Vila Bacanga, MA, 65085-580 São Luís, Maranhão, Brazil.

Received: 7 February 2017 Accepted: 24 May 2017

Published online: 26 June 2017

References

1. Neel JV. Diabetes mellitus: a "thrifty" genotype rendered detrimental by "progress"? Am J Hum Genet. 1962;14:353-62.

2. Barker DJ, Winter PD, Osmond C, Margetts B, Simmonds SJ. Weight in infancy and death from ischaemic heart disease. Lancet. 1989;2(8663):577-80.

3. Barker DJ, Eriksson JG, Forsen T, Osmond C. Fetal origins of adult disease: strength of effects and biological basis. Int J Epidemiol. 2002;31(6):1235-9.

4. Cleal JK, Poore KR, Boullin JP, Khan O, Chau R, Hambidge O, et al. Mismatched pre- and postnatal nutrition leads to cardiovascular dysfunction and altered renal function in adulthood. Proc Natl Acad Sci U S A. 2007;104(22):9529-33.

5. Barker DJ, Osmond C, Golding J, Kuh D, Wadsworth ME. Growth in utero, blood pressure in childhood and adult life, and mortality from cardiovascular disease. BMJ. 1989;298(6673):564-7.

6. Eriksson JG, Lindi V, Uusitupa M, Forsen TJ, Laakso M, Osmond C, et al. The effects of the Pro12Ala polymorphism of the peroxisome proliferatoractivated receptor-gamma2 gene on insulin sensitivity and insulin metabolism interact with size at birth. Diabetes. 2002;51(7):2321-4.

7. Forrester TE, Badaloo AV, Boyne MS, Osmond C, Thompson D, Green C, et al. Prenatal factors contribute to the emergence of kwashiorkor or marasmus in severe undernutrition: evidence for the predictive adaptation model. PLoS ONE. 2012;7(4):e35907.

8. Hardy R, Lawlor DA, Kuh D. A life course approach to cardiovascular aging. Future Cardiol. 2015;11(1):101-13. 
9. Wells JC. The thrifty phenotype: an adaptation in growth or metabolism? Am J Hum Biol. 2011;23(1):65-75.

10. Gillette MT, Lohman BJ, Neppl TK. Lower levels of maternal capital in early life predict offspring obesity in adulthood. Ann Hum Biol. 2016;04:1-9.

11. Wells JC. A critical appraisal of the predictive adaptive response hypothesis. Int J Epidemiol. 2012;41(1):229-35.

12. Camelo LV, Giatti L, Neves JA, Lotufo PA, Bensenor IM, Chor D, et al. Life course socioeconomic position and C-reactive protein: mediating role of health-risk behaviors and metabolic alterations. The Brazilian Longitudinal Study of Adult Health (ELSA-Brasil). PLoS ONE. 2014;9(10):e108426.

13. Bann D, Cooper R, Wills AK, Adams J, Kuh D. Socioeconomic position across life and body composition in early old age: findings from a British birth cohort study. J Epidemiol Community Health. 2014;68(6):516-23.

14. Barros AJ, Victora CG, Horta BL, Goncalves HD, Lima RC, Lynch J. Effects of socioeconomic change from birth to early adulthood on height and overweight. Int J Epidemiol. 2006;35(5):1233-8.

15. Heraclides A, Brunner E. Social mobility and social accumulation across the life course in relation to adult overweight and obesity: the Whitehall II study. J Epidemiol Community Health. 2010;64(8):714-9.

16. Aitsi-Selmi A, Batty GD, Barbieri MA, Silva AA, Cardoso VC, Goldani MZ, et al. Childhood socioeconomic position, adult socioeconomic position and social mobility in relation to markers of adiposity in early adulthood: evidence of differential effects by gender in the 1978/79 Ribeirao Preto cohort study. Int J Obes (Lond). 2013;37(3):439-47.

17. Rasella D, Aquino R, Barreto ML. Impact of income inequality on life expectancy in a highly unequal developing country: the case of Brazil. J Epidemiol Community Health. 2013;67(8):661-6.

18. Silva AA, Silva LM, Barbieri MA, Bettiol H, Carvalho LM, Ribeiro VS, et al. The epidemiologic paradox of low birth weight in Brazil. Rev Saude Publica. 2010;44(5):767-75.

19. Veloso HJ, Silva AA, Barbieri MA, Goldani MZ, Lamy Filho F, Simoes VM, et al. Secular trends in the rate of low birth weight in Brazilian State Capitals in the period 1996 to 2010. Cad Saude Publica. 2013;29(1):91-101.

20. Petersen MB, Aaroe L. Birth weight and social trust in adulthood: evidence for early calibration of social cognition. Psychol Sci. 2015;26(11):1681-92.

21. Power $C$, Jefferis $B$ J, Manor $O$, Hertzman C. The influence of birth weight and socioeconomic position on cognitive development: does the early home and learning environment modify their effects? J Pediatr. 2006;148(1):54-61.

22. Spencer N. Accounting for the social disparity in birth weight: results from an intergenerational cohort. J Epidemiol Community Health. 2004;58(5):418-9.

23. Astone NM, Misra D, Lynch C. The effect of maternal socio-economic status throughout the lifespan on infant birthweight. Paediatr Perinat Epidemiol. 2007;21(4):310-8.

24. Collins JW, Rankin KM, David RJ. Low birth weight across generations: the effect of economic environment. Matern Child Health J. 2011;15(4):438-45.

25. Bygbjerg IC, Meyrowitsch DW. Global transition in health. Ugeskr Laeger. 2006;168(36):3018-20.

26. Amuna P, Zotor FB. Epidemiological and nutrition transition in developing countries: impact on human health and development. Proc Nutr Soc. 2008;67(1):82-90.

27. Barbieri MA, Bettiol H, Silva AA, Cardoso VC, Simoes VM, Gutierrez MR, et al. Health in early adulthood: the contribution of the 1978/79 Ribeirao Preto birth cohort. Braz J Med Biol Res. 2006;39(8):1041-55.

28. Cardoso VC, Simoes VM, Barbieri MA, Silva AA, Bettiol H, Alves MT, et al. Profile of three Brazilian birth cohort studies in Ribeirao Preto, SP and Sao Luis. MA Braz J Med Biol Res. 2007;40(9):1165-76.

29. Keys A, Fidanza F, Karvonen MJ, Kimura N, Taylor HL. Indices of relative weight and obesity. J Chronic Dis. 1972;25(6):329-43.

30. Silvestrin S, Silva CH, Hirakata VN, Goldani AA, Silveira PP, Goldani MZ Maternal education level and low birth weight: a meta-analysis. J Pediatr (Rio J). 2013:89(4):339-45

31. Ludwig J, Sanbonmatsu L, Gennetian L, Adam E, Duncan GJ, Katz LF, et al. Neighborhoods, obesity, and diabetes-a randomized social experiment. N Engl J Med. 2011;365(16):1509-19.

32. Muraro AP, Goncalves-Silva RM, Ferreira MG, Sichieri R. Effects of social mobility from childhood to adolescence on BMI. Public Health Nutr. 2015;11:1-8.

33. Albrecht SS, Gordon-Larsen P. Socioeconomic gradients in body mass index (BMI) in US immigrants during the transition to adulthood: examining the roles of parental education and intergenerational educational mobility. J Epidemiol Community Health. 2014;68(9):842-8.
34. McEwen BS, Gianaros PJ. Central role of the brain in stress and adaptation: links to socioeconomic status, health, and disease. Ann N Y Acad Sci. 2010;1186:190-222.

35. Kagura J, Adair LS, Pisa PT, Griffiths PL, Pettifor JM, Norris SA. Association of socioeconomic status change between infancy and adolescence, and blood pressure, in South African young adults: Birth to Twenty Cohort. BMJ Open. 2016;6(3):e008805.

36. Zheng $\mathrm{H}$, Tumin D. Variation in the effects of family background and birth region on adult obesity: results of a prospective cohort study of a Great Depression-era American cohort. BMC Public Health. 2015;15:535.

37. Gigante DP, Minten GC, Horta BL, Barros FC, Victora CG. Nutritional evaluation follow-up of the 1982 birth cohort, Pelotas, Southern Brazil. Rev Saude Publica. 2008;42(Suppl 2):60-9.

38. Wagner KJ, Bastos JL, Navarro A, Boing AF. Socio-economic life course and obesity among adults in Florianopolis, southern Brazil. Gac Sanit. 2017;29.

39. Cho WK, Suh BK. Catch-up growth and catch-up fat in children born small for gestational age. Korean J Pediatr. 2016;59(1):1-7.

40. Sutharsan R, O'Callaghan MJ, Williams G, Najman JM, Mamun AA. Rapid growth in early childhood associated with young adult overweight and obesity - evidence from a community based cohort study. J Health Popul Nutr. 2015;33(1):13.

41. Mesquita DN, Barbieri MA, Goldani HA, Cardoso VC, Goldani MZ, Kac G, et al. Cesarean section is associated with increased peripheral and central adiposity in young adulthood: cohort study. PLoS ONE. 2013;8(6):e66827.

42. Bernardi JR, Pinheiro TV, Mueller NT, Goldani HA, Gutierrez MR, Bettiol H, et al. Cesarean delivery and metabolic risk factors in young adults: a Brazilian birth cohort study. Am J Clin Nutr. 2015;102(2):295-301.

43. Mueller NT, Bakacs E, Combellick J, Grigoryan Z, Dominguez-Bello MG. The infant microbiome development: mom matters. Trends Mol Med. 2015;21(2):109-17.

44. Groer MW, Gregory KE, Louis-Jacques A, Thibeau S, Walker WA. The very low birth weight infant microbiome and childhood health. Birth Defects Res $C$ Embryo Today. 2015;105(4):252-64.

45. Li HT, Zhou YB, Liu JM. The impact of cesarean section on offspring overweight and obesity: a systematic review and meta-analysis. Int J Obes (Lond). 2013;37(7):893-9.

46. Cameron AJ, Spence AC, Laws R, Hesketh KD, Lioret S, Campbell KJ. A review of the relationship between socioeconomic position and the earlylife predictors of obesity. Curr Obes Rep. 2015;4(3):350-62.

47. Kuh D, Ben-Shlomo Y. A Life Course Approach to Chronic Disease Epidemiology: Tracing the Origins of III-Health From Early to Adult Life. Oxford: Oxford University Press; 2004.

48. Simoes VM, Barbieri MA, Silva AA, Batista RF, Alves MT, Cardoso VC, et al. Perinatal and early adulthood factors associated with adiposity. Cad Saude Publica. 2012;28(7):1381-93.

49. Rossi IA, Rousson V, Viswanathan B, Bovet P. Gender and socioeconomic disparities in BMI trajectories in the Seychelles: a cohort analysis based on serial population-based surveys. BMC Public Health. 2011;11:912.

50. Tarrade A, Panchenko P, Junien C, Gabory A. Placental contribution to nutritional programming of health and diseases: epigenetics and sexual dimorphism. J Exp Biol. 2015;218(Pt 1):50-8.

51. Case A, Menendez A. Sex differences in obesity rates in poor countries: evidence from South Africa. Econ Hum Biol. 2009;7(3):271-82.

52. Barbieri MA, Portella AK, Silveira PP, Bettiol H, Agranonik M, Silva AA, et al. Severe intrauterine growth restriction is associated with higher spontaneous carbohydrate intake in young women. Pediatr Res. 2009;65(2):215-20.

53. Ludwig J, Duncan GJ, Gennetian LA, Katz LF, Kessler RC, Kling JR, et al. Neighborhood effects on the long-term well-being of low-income adults. Science. 2012;337(6101):1505-10. 